\title{
Geometrically Nonlinear Stability of Curved Continuous Rigid Frame Bridges with Initial High Pier Imperfections at Largest Cantilever Stage
}

\author{
Guohua Song, Minghui Li, and Delu Che
}

\begin{abstract}
In this study, we investigated the geometrically nonlinear stability (GNS) of curved continuous rigid frame bridges (CRFB) with initial high pier imperfections at the largest cantilever stage. The stability safety factors were computed and compared for models in an ideal state, initial material imperfection state, initial tilt sate, initial bend state, or with different pier types, respectively. The stability safety factors decrease when geometrically nonlinear effects are considered, and decrease to greater extent when the initial material imperfection appears in the middle and lower portions of the pier. A cross section in the double-limb piers causes even greater decrease in stability. Initial tilt and initial bend also decrease stability, especially the latter - in practice, it is crucial to reduce initial bend as much as possible to ensure a safe structure. These factors affect stability to nearly the same extent regardless of whether a double-limb pier or single-limb pier is utilized. Taken together, these results suggest that GNS analysis is necessary to fully comprehensively assess the safety of a curved CRFB with high piers.
\end{abstract}

Index Terms - Curved continuous rigid frame bridge (CRFB), high pier, geometrically nonlinear analysis (GNS), stability safety factor, finite element (FE) method, initial imperfections.

\section{INTRODUCTION}

Curved bridges are commonly built in mountainous areas per their unique requirements for specific alignment; high piers are typically built into continuous rigid frame bridges (CRFBs) to cover the deep valleys in these areas, as well. Long-span thin-walled box girders and high piers drive down the overall rigidness of the bridge and make the forces and deformations of the pier-girder structure exceptionally complex. A continuous rigid frame is usually built into curved long-span bridges with high piers via the segmental cantilever construction technique. At the construction stage, the T-type rigid frame is weakly constrained and its integral rigidity is small. These factors altogether significantly affect the stability of the rigid frame [1]. The stability of a T-type rigid frame as calculated by traditional linear elasticity theory is generally inaccurate and inappropriate for actual construction

Manuscript received February 2, 2018; revised May 1, 2018. This work was supported by the National Natural Science Foundation of China under Gran U1304515

Guohua Song is with the School of Civil Engineering, Zhengzhou Univeisity, Zhenghzou, China (email: guohuasong_309@163.com).

Minghui $\mathrm{Li}$ is with China Construction First Building (Group) Corporation Limited, Shanghai, China (email: liminghui05@163.com).

Delu Che is with Henan Provincial Communications Planning and Design Institute Corporation Limited, Zhengzhou, China (email: chedelu92@163.com). practices [2], [3]. The largest cantilever stage is the control stage for long-span curved bridges with high piers encompassing both construction and service stages [4]. Initial imperfections are inevitable in practice. Previous researchers have investigated their influence on CRFBs [5]-[7], but there has been relatively little research on their effect on curved CRFBs specifically.

Wang and $\mathrm{He}$ [4], [8], [9] investigated the relationship between the critical stability coefficient and design parameters such as pier slenderness ratio, curve central angle, and temperature in curved box-girder bridges with high piers at construction and service stages; this investigation included the geometric nonlinearity and material nonlinearity of the bridge structure. A. Sevket [10] found that segmental construction stage analysis via time-dependent material properties and geometric nonlinearity can reveal the real behavior of concrete bridges. N. Mohammad et al [11]) examined the buckling response of straight and initially bent (i.e., geometrically imperfect) end-bearing piles in soil subjected to axial load through finite element (FE) method exclusively under geometric and material nonlinearities. Geometric nonlinearity indeed affects the state of the bridge and thus should be a crucial factor in the design and construction control calculation of the structure [12]. Feng et al. [13] and Luo et al. [14] developed an analytical theory and computational method for curved thin-walled box girders which include shear lag effect and geometric nonlinearity, with corresponding nonlinear governing differential equations for the girder. Lateral wind loads markedly affect the stability of bridge girders during the construction stage, at which point the deck is not yet structurally effective. Wind-load cases can be designed to assess the overall multi-girder system stability and to determine the required strength of the girder bracing between individual girders; these results can be synthesized into simplified wind-loading cases suitable for use in bridge design [15].

In conclusion, it is very necessary to analyze the GNS of curved CRFBs. We did so in this study at the largest cantilever stage to investigate the influence of initial imperfections in the high piers, such as initial material imperfections or geometrical imperfections. We used a curved CRFB in a mountainous area of Western China as a practical engineering prototype to investigate stability under various construction loads, wind loads, and accidental loads during construction. We used the finite element (FE) program Midas/Civil to build bridge models at the largest cantilever stage, analyzed the construction stabilities of the models and their relationship with pier parameters, and established a 
series of conclusions as discussed below.

\section{Method USED IN NONLINEAR ANALYSIS}

Solid mechanics consists of three basic equations for equilibrium, physics, and geometric motion. The fundamental conditions meeting the above equations comprise classical linear theory, which consists of three assumptions: ideal constrains, materials satisfying Hook's law, and tiny deformations. It is difficult to meet the above assumptions simultaneously in practice, so the original linear problem is typically converted into a nonlinear problem. As the pier height and flexibility of the bridge increase during construction, great deformation emerges at the top of the pier under gravity, wind, and other loads. The condition of tiny displacements cannot be satisfied under these conditions, so it is necessary to investigate the nonlinear stability of the bridge because its linear stability cannot be accurately assessed.

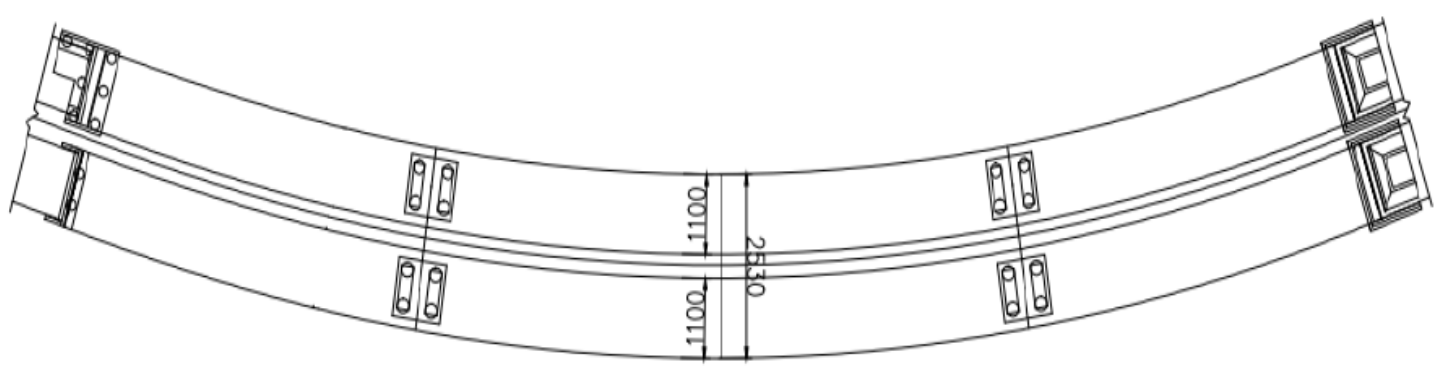

Fig. 1 Layout plan of bridge.

For a structure with large deformation, the following equation is preferable:

$$
F=R U, \varepsilon=f(U)
$$

where $F$ is the displacement tensor; $R$ is the rotational displacement tensor; and $U$ is the deformation tensor; and $\varepsilon$ is the strain tensor.

In practice, structural deformations are determined by the deformation tensor. In solving large deformation problems with equation (1), the rotation deformation must be removed from the whole deformation first. If there is excessive rotation deformation, however, then the correct relationship between strain and displacement cannot be obtained via equation (1) and the geometrically nonlinear effects must be considered. Here, we analyze the GNS for curved CRFBs with high piers at the largest cantilever stage to account for this.

We used the co-rotational method for geometrically nonlinear analysis in the Midas/Civil program. This allowed us to consider geometrically nonlinear effects by pasting deformation element deformations into the co-rotational coordinate system. There are three methods for solving a geometrically nonlinear equation in Midas/Civil: the New-Raphson method, arc length method, and displacement control method. The GNS analysis process can be summarized as follows.

(1) Define all the loads to one load case: The most outstanding characteristic of nonlinear analysis is that loads cannot be overlaid, so after determining the loads to be analyzed nonlinearly, define all the loads to one load case or impose the loads orderly per the situation at hand. (In our case, only the New-Raphson method is applicable.)

(2) Define the controlling items of nonlinear analysis, chose geometric nonlinearity, then add the load case into the geometric nonlinearity and define the load steps: A node must serve as a control point for analysis via displacement controlling method. Static analysis is first conducted, and then the control point is determined by buckling analysis (including the size and direction of the point). The load step can be adjusted as necessary to make the results converge.

(3) Run analysis.

(4) View the results and confirm the stability safety factor of the structure. View the stage time history charts, extract the curve graph of load to displacement, and define the loading coefficient at the peak point as the stability safety factor.

\section{MODEL BUILDING}

\section{A. Bridge Design}

Curved CRFB models with high-piers were built with spans of $61+104+61 \mathrm{~m}$, curvature radius of $348 \mathrm{~m}$, and pier height of $63 \mathrm{~m}$, and central line of piers normal to the central line of the roadway. The superstructure had a cross slope of 5 percent and was $22 \mathrm{~m}$ wide. It was composed of two girders, each a single-box single-room section with width of $11 \mathrm{~m}$ and varying height (by quadratic parabola). The piers were $63 \mathrm{~m}$ high. The layout plan was shown in Fig. 1. Other design details were as follows.

\section{1) Main construction materials}

a) Concrete: C50 was for superstructure, C40 was for piers and cross beams.

b) Prestressed tendon: Prestressed tendons were considered only in the longitudinal direction with a nominal diameter of $15.2 \mathrm{~mm}$, comprised of a steel strand of seven wires with high strength and low relaxation. The tendons had elasticity module $E_{\mathrm{p}}=1.95 \times 10^{5} \mathrm{Mpa}$, standard strength $f_{\mathrm{pk}}=1860 \mathrm{Mpa}$, and less than $2.5 \%$ of stress relaxation rate in 1000 hours; a large tonnage grouped anchor system and vacuum mortar suction technique were used to fabricate them.

c) Rebars: The main reinforcements were HRB400.

d) Bearings: Seismic steel bearings were used for end bearings; WKJ-QZ4000DX for the inner side and WKJ-QZ4000SX for the outer side.

2) Box girder size

Curved CRFB models with high-piers were built with 
spans of $61+104+61 \mathrm{~m}$, curvature radius of $348 \mathrm{~m}$, and pier height of $63 \mathrm{~m}$, and central line of piers normal to the central line of the roadway. The superstructure had a cross slope of 5 percent and was $22 \mathrm{~m}$ wide. It was composed of two girders, each a single-box single-room section with width of $11 \mathrm{~m}$ and varying height (by quadratic parabola). The piers were $63 \mathrm{~m}$ high. The layout plan was shown in Fig. 2.

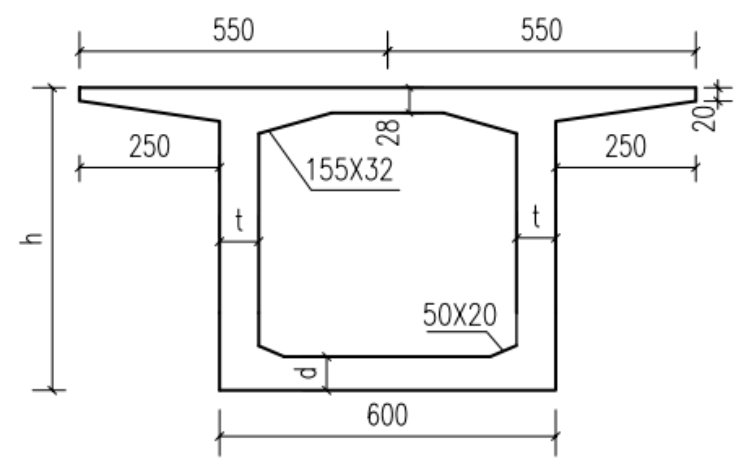

Fig. 2. Cross section of box girder at pier top (unit: $\mathrm{cm}$ ).

\section{3) Piers}

The piers of the bridge were double-limb thin-walled piers with cross beams. Each limb had a rectangular cross section of $2 \times 6 \mathrm{~m}$ and the distance between two limbs was $5 \mathrm{~m}$. There was a cross beam with an interval of 21 meters between any two limbs.

\section{4) Construction process}

The prestressed curved CRFB was constructed in order as the pile foundation and caps, piers, and casting segment 0 . All segments but the closure segment and cast-in-site segment on the side span were cast successively via hanging basket cantilever pour symmetrically. Eleven segments were constructed on both sides simultaneously. The steel tendons were prestressed after each segment was finished. This process continued until the largest cantilever stage was completed.

\section{B. Building FE Models}

As mentioned above, we used the Midas/Civil program in this study; it is commonly used to analyze bridge structures, underground structures, industrial buildings, airports, dams, harbors, and other engineered structures. We modeled the superstructures with beam elements. The girder and piers were rigidly connected, the bottom of piers was comprised of conventional bearings, the supports on both ends were elastically connected according to support parameters, and the lumped mass method was used for analysis. The FE model of the bridge at the finished bridge stage is shown in Figure. 3.

For the bridge under normal construction at the largest cantilever stage, the construction loads are as follows: (i) Gravity; (ii) Longitudinal prestressing forces; (iii) Loads from construction equipment and materials placed unevenly; (iv) Gravity of the hanging basket with dynamic effect $(1200 \mathrm{kN}$, with dynamic coefficient of 1.2 on one side and 0.8 on the other side); (v) Wind loads in the lateral direction. The bridge becomes softer when pier height is taller and thus more sensitive to wind load, so it is necessary to take wind into account when analyzing structural stability. Wind pressure in the transverse direction of piers was determined according to
Wind-resistant Design Specification for Highway Bridges (JTGT D60-01-2015 2015) [16]. The loads acting on the structure were: (i) + (ii) + (iii) + (iv) + (v).

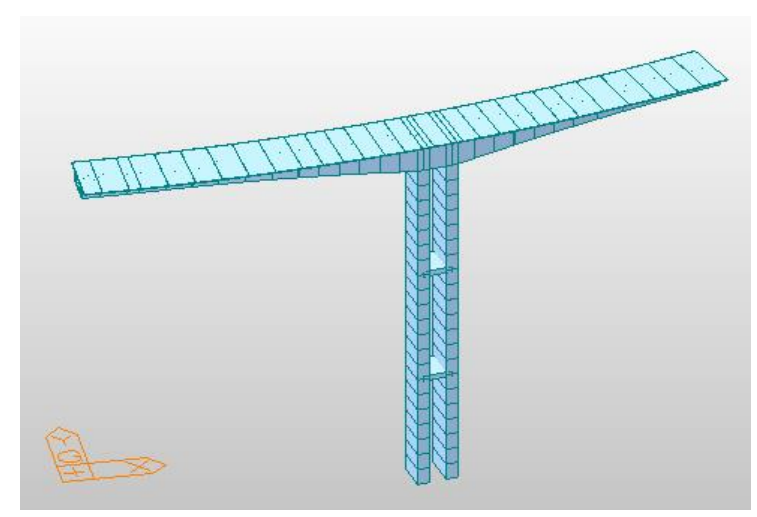

Fig. 3. FE model at largest cantilever stage.

\section{GNS ANALYSIS IN IDEAL STATE}

In this section, the structure is assumed to be in an ideal state with no initial imperfections. After running GNS analysis, the geometric nonlinearity curve of loads versus displacements of high-piers in the ideal state was obtained as shown in Fig. 4.

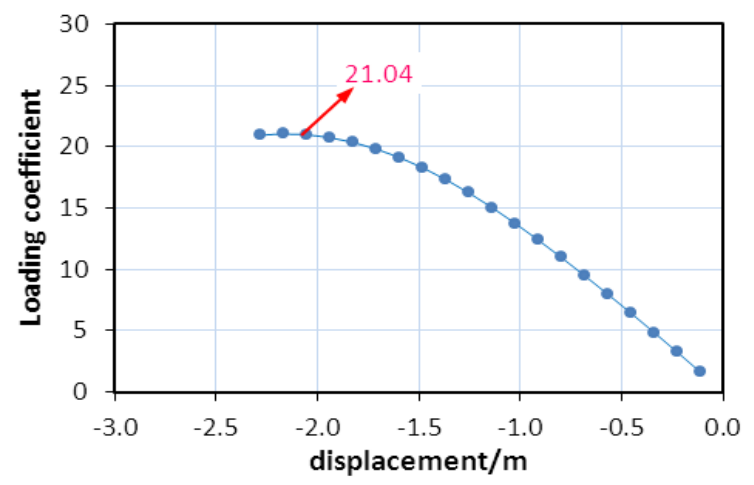

Fig. 4. Loads versus displacements in ideal state.

The nonlinear stability safety factor in ideal state is 21.04 , which is smaller than the linear stability safety factor 25.78 (18.4\% difference) as detailed in Table I.

TABLE I: STABILITY SAFETy FACTORS IN IDEAL STATE

\begin{tabular}{llll}
\hline Stability type & $\begin{array}{l}\text { Linear } \\
\text { stability } \kappa\end{array}$ & $\begin{array}{l}\text { Nonlinear } \\
\text { stability } \kappa_{\mathrm{n}}\end{array}$ & $\begin{array}{l}\left(\kappa-\kappa_{\mathrm{n}}\right) / \kappa \\
(\%)\end{array}$ \\
\hline Stability safety factor & 25.78 & 21.04 & 18.4 \\
\hline \hline
\end{tabular}

Table I shows where the stability safety factor of the bridge decreases when the geometrically nonlinear effect is considered. The structure buckles along the bridge in linear analysis, but displacement increases at the top of the pier along the bridge as construction load increases even under normal construction; the effect of large deformation is enhanced, which decreases the ultimate capacity and weakens the stability safety factor of the structure. In practice, it is necessary to properly account for geometrically nonlinear effects on structural stability to accurately evaluate safety and avoid accidents on the bridge. 


\section{GNS ANALYSIS IN STATE OF INITIAL MATERIAL IMPERFECTIONS}

Suppose that there is a serious (and undiscovered) quality problem with the concrete in one segment when a high-pier is poured. The influence of this kind of initial material imperfection is discussed in this section.

The pier column of bridge model was divided into seven pour segments each $9 \mathrm{~m}$ long and numbered as 1 to 7 from top to bottom. The initial material imperfections were simulated by degrading the concrete strength [17]. The original concrete of the pier was $\mathrm{C} 40$ in strength; the degraded concrete was C20. The loads imposed on the structure were same as those described in Section II. The GNS safety of the bridge was researched with each successive concrete segment having material imperfections. After seven corresponding computation iterations, the stability safety factors of the bridge were determined as shown in Fig. 5. The curves of loads versus displacements in segment 3 and segment 7 with initial material imperfections are shown in Fig. 6.

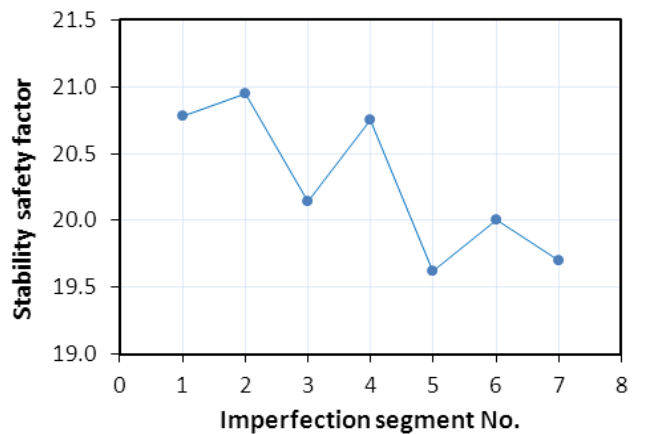

Fig. 5. Stability safety factors with each pier segment having initial material.

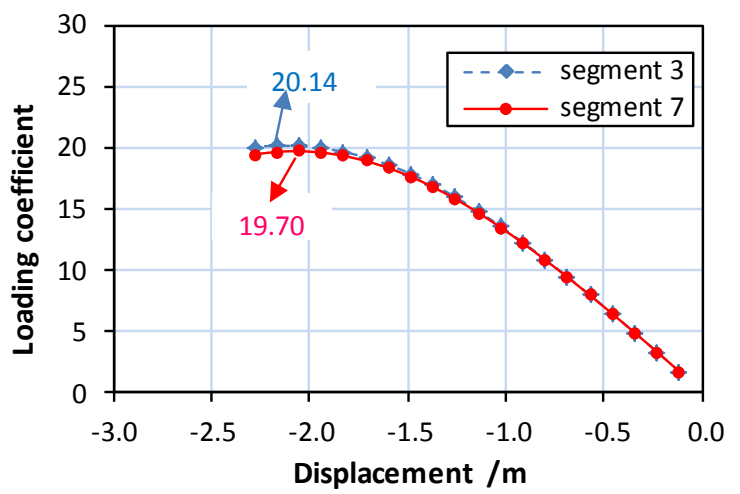

Fig. 6. Curves of loads versus displacements with initial material imperfections.

Fig. 5 shows where initial material imperfections indeed decrease structural stability. In general, segments at lower locations have greater impact on stability, as they bear greater stress than upper segments; as the loads increase, the lower segments yield first. If the concrete has quality imperfections, it is crushed rapidly, a plastic hinge appears, and then the pier reaches its ultimate capacity. The stability safety factors of segment 3 and segment 5 decreased to greater extent than the others due to the cross beams in the two segments. A cross beam strengthens the stability of the high-pier. If an initial material imperfection exists both in cross beams and the pier body, the stability markedly decreases; this tendency is also illustrated in Fig. 5.

\section{GNS ANALYSIS IN STATE OF INITIAL GEOMETRIC IMPERFECTIONS}

Initial geometric imperfections create another issue that must be taken into account per the unique conditions of slip-form construction, which is typically applied for pier erection in CRFBs. The actual line types of piers are not ideal for many reasons. Deviation exists between the actual line style and design alignment, and often presents as a tilt or bend. There are many factors responsible for such deviation, for example, the accumulation of measurement error impacts the canter line of the pier body, formwork part sizes, and elevation at the pier top. Flatness in the formwork surface and slab ends can also lead to deviation. These factors must be properly accounted for to accurately evaluate structural stability.

In practice, initial geometric imperfections are highly irregular. It is difficult to completely reflect the actual conditions. With reference to the literature [18], [19], we simulated the structure morphology with initial imperfections as a buckling mode and analyzed the linear stability of the structure accordingly. We assumed the results would be conservative, but assert that this method is advantageous in terms of stability and safety. Simulating the initial geometrical imperfections was a two-part process: (a) distribution of imperfections and (b) peak of imperfections. The peak of imperfections was modeled according to the literature and relevant codes [5]-[7]. We also divided initial geometric imperfections into two categories: initial tilt and initial bend.

\section{A. Influence of Initial Tilt on Structure Stability}

Suppose the high-pier has a random initial tilt under many actions during the engineering process. We modeled the initial tilt of the pier body through consistent imperfect buckling analysis. Different researchers have taken different initial tilt values of the pier body for this purpose [5]-[7]. Generally, specific ratios of tilt to pier height (e.g., 1/1000, $1 / 2000$, and 1/3000) are utilized as constant values. Here, the height of model piers is $63 \mathrm{~m}$ and the initial tilt values are 0.03 , 0.06 , and $0.09 \mathrm{~m}$.

In a previous study conducted in our laboratory, we considered the first-order bulking mode of the pier to be a classic tilt mode. Here, the influence of initial tilt on structure stability was based on the first-order bulking mode of the pier.

The FE models were built via the following step-wise process.

(1) Determine the values of initial imperfections.

(2) Compute the ratio of initial imperfections to displacement at pier top in the first-order buckling vector.

(3) Multiply all the buckling vectors of nodes by the ratio determined in Step (2). Their products can be regarded as the initial imperfections of nodes.

(4) Substitute the initial imperfections of nodes in Step (3) into the model; modify the coordinates of every node after introducing the initial imperfections to obtain the new updated model.

\section{1) Main construction materials}

We analyzed the linear stability of a structure with initial tilt in the pier body. The stability safety factor $\kappa_{\mathrm{t}}$ in the initial tilt state was computed and compared against $\kappa$ in the ideal state. The results are shown in Table II. 
TABLE II: STABILITY SAFETY FACTORS IN INITIAL TILT STATE VERSUS IDEAL STATE

\begin{tabular}{llll}
\multicolumn{4}{c}{ IDEAL STATE } \\
\hline \hline $\begin{array}{l}\text { Initial tilt value } \\
(\mathrm{m})\end{array}$ & $\begin{array}{l}\text { In initial tilt } \\
\text { state } \kappa_{\mathrm{t}}\end{array}$ & In ideal state & $\left(\kappa-\kappa_{\mathrm{t}}\right) / \kappa$ \\
\hline 0.03 & 25.776 & 25.78 & 0 \\
0.06 & 25.773 & 25.78 & 0 \\
0.09 & 25.771 & 25.78 & 0 \\
\hline \hline
\end{tabular}

Initial tilt has little influence on the linear stability of the structure; the stability safety factor is nearly the same between ideal and initially imperfect states as the initial tilt value increases. However, we only assessed the linear stability of the structure and thus the influence of initial tilt is not perfectly represented. In practice, measures should be taken to reduce the initial tilt of the pier body.

\section{2) Influence of initial tilt on nonlinear stability}

In practical engineering, as discussed above, structural stability cannot be assessed via linear analysis. It is generally acknowledged that the first type of stability exceeds the second type of stability [20]. Here, we investigated the nonlinear stability of the structure with geometrically nonlinear effects. The initial tilt values and loads imposed were the same as those described in Section VI.A. 1).

The nonlinear stability of the structure with initial tilt imperfections in the pier body was analyzed. The stability safety factors were computed and compared with those in the ideal state as shown in Table III. The curves of loads versus displacements are shown in Fig. 7 for models with initial tilt of $0.03 \mathrm{~m}$ and $0.09 \mathrm{~m}$.

TABLE III: STABILITY SAFETY FACTORS IN INITIAL TILT STATE VERSUS IDEAL STATE

\begin{tabular}{llllll}
\hline \hline $\begin{array}{l}\text { Initial tilt } \\
\text { value }(\mathrm{m})\end{array}$ & $\begin{array}{l}\text { In initial tilt } \\
\text { state } \kappa_{\mathrm{tn}}\end{array}$ & $\begin{array}{l}\text { In ideal } \\
\text { state } \kappa_{\mathrm{n}}\end{array}$ & $\begin{array}{l}\left(\kappa_{\mathrm{n}}-\kappa_{\mathrm{tn}}\right) / \kappa_{\mathrm{n}} \\
(\%)\end{array}$ & $\begin{array}{l}\text { Linear } \\
\text { stability } \kappa\end{array}$ & $\begin{array}{l}\left(\kappa-\kappa_{\mathrm{tn}}\right) / \kappa \\
(\%)\end{array}$ \\
\hline 0.03 & 20.80 & 21.04 & 0.14 & 25.78 & 19.32 \\
0.06 & 20.37 & 21.04 & 3.18 & 25.78 & 20.99 \\
0.09 & 19.82 & 21.04 & 5.80 & 25.78 & 23.12 \\
\hline \hline
\end{tabular}

Table III shows where structure stability is lower in the initial tilt state than the ideal state when the geometrically nonlinear effect was considered; the greatest extent of decline was $5.80 \%$ to $20 \%$ in comparison with the linear stability results. In effect, initial tilt markedly decreases structural stability. It is not sufficient merely to assess linear stability to ensure structural safety - the influence of geometrically nonlinear factors must also be taken under consideration. Measures must be taken to reduce initial tilt in building a safe and stable structure.

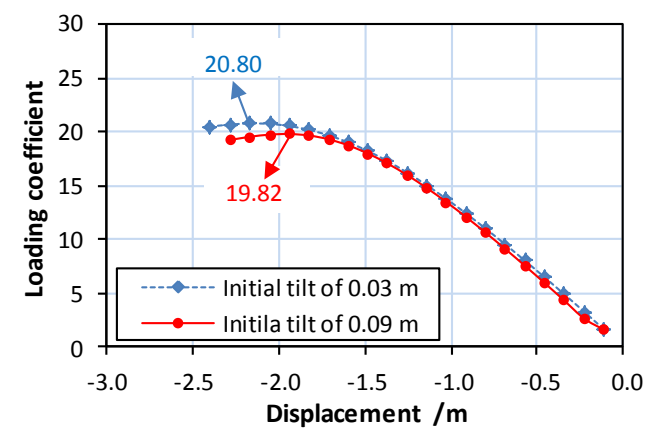

Fig. 7. Curves of loads versus displacements in initial tilt state.

\section{B. Influence of Initial Bend on Structure Stability}

Piers are poured segmentally in the actual construction process, so misalignment may appear between any two adjacent segments. Misalignment error is accumulated as the rest of the pier body is poured. This may force the central line of the pier into an eccentric compression bar which will bend under gravity and other loads. Similar to initial tilt, the maximum initial bend of the pier body is disputed among researchers [5]-[7]. In this paper, the maximum value was taken as $1 / 1000,1 / 2000$, or $1 / 3000$. The third-order bulking mode was adopted in stability analysis to model the initial bend, as it is the classic bending modal in the first modes. The FE models and loads were constructed in the same manner as described in Section V.A.

\section{1) Influence of initial bend on linear stability}

Different FE models were built with different initial bend values and analyzed for linear stability in comparison against the ideal state. The resulting stability safety factors are shown in Table IV.

TABLE IV: LINEAR STABILITY SAFETY FACTORS IN INITIAL BEND STATE VERSUS IDEAL STATE

\begin{tabular}{llll}
\hline \hline \multirow{2}{*}{ Initial bend value } & $\begin{array}{l}\text { In initial bend } \\
\text { state } \kappa_{\mathrm{bl}}\end{array}$ & $\begin{array}{l}\text { In ideal state } \\
\kappa\end{array}$ & $\begin{array}{l}\left(\kappa-\kappa_{\mathrm{bl}}\right) / \kappa \\
(\%)\end{array}$ \\
\hline $1 / 3000$ & 25.75 & 25.78 & 0.12 \\
$1 / 2000$ & 25.61 & 25.78 & 0.66 \\
$1 / 1000$ & 25.23 & 25.78 & 2.13 \\
\hline \hline
\end{tabular}

Table IV shows where initial bend has little influence on the linear stability of the structure. The linear stability safety factor decreases as the initial bend of the pier body increases. The maximum decrease was $2.13 \%$. Initial bend does have greater influence on the linear stability of the structure than initial tilt, so it should be minimized as much as possible in practice.

\section{2) Influence of initial bend on nonlinear stability}

Assessment of linear stability alone is not sufficient to ensure structural safety, as discussed above. We investigated the influence of geometrically nonlinear effects in the initial bend state as reported in Table V. The curves of loads versus displacements in models with initial bend values of $1 / 3000$ and 1/1000 are shown in Fig. 8.

TABLE V: NONLINEAR STABILITY SAFETy FACTORS IN INITIAL BEND STATE VERSUS IDEAL STATE

\begin{tabular}{llllll}
\hline \hline $\begin{array}{l}\text { Initial } \\
\text { bend }\end{array}$ & $\begin{array}{l}\text { In initial bend } \\
\text { state } \kappa_{\text {bn }}\end{array}$ & $\begin{array}{l}\text { In ideal } \\
\text { state } \kappa_{\mathrm{n}}\end{array}$ & $\begin{array}{l}\left(\kappa_{\mathrm{n}}-\kappa_{\text {bn }}\right) / \kappa_{\mathrm{n}} \\
(\%)\end{array}$ & $\begin{array}{l}\text { Linear } \\
\text { stability } \kappa\end{array}$ & $\begin{array}{l}\left(\kappa-\kappa_{\text {bn }}\right) / \kappa \\
(\%)\end{array}$ \\
\hline $1 / 3000$ & 20.29 & 21.04 & 3.56 & 25.78 & 21.29 \\
$1 / 2000$ & 19.27 & 21.04 & 8.41 & 25.78 & 25.25 \\
$1 / 1000$ & 17.28 & 21.04 & 17.87 & 25.78 & 32.97 \\
\hline \hline
\end{tabular}

Table V shows where the nonlinear stability safety factors of the structure decrease considerably in the initial bend state respective to those in the ideal state - the maximum level of decline was $17.8 \%$. Nonlinear stability safety factors decrease significantly as initial bend increases. Compared with linear stability safety factors, the stability of structure decreases more than $30 \%$. Initial bend must be carefully minimized to ensure a safe structure. 


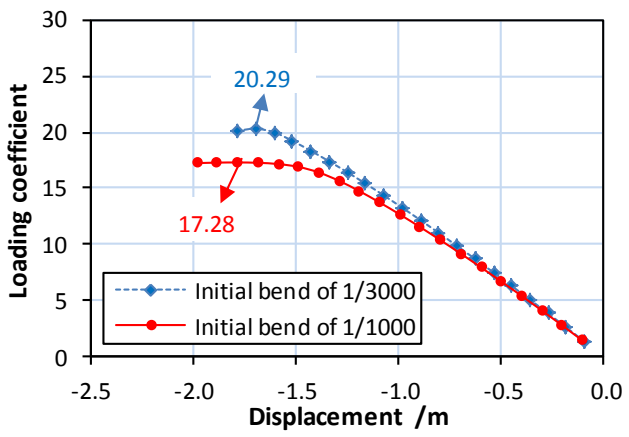

Fig. 8. Curves of loads versus displacements in initial bend state.

\section{GNS ANALYSIS OF DIFFERENT PIER TYPES}

CRFBs are pier-girder consolidation systems. Pier rigidness has a strong influence on the overall stability of these bridge structures. In practice, there are two types of CRFB piers: double-limb piers and single-limb piers with thin walls. We assessed the influence of four pier types on the nonlinear stability of the CRFB structure: a double-limb pier with cross beam (DLP with CB), double-limb pier without cross beam (DLP without CB), single-limb hollow pier with wall thickness of $0.5 \mathrm{~m}$ (SLHP with W0.5), and single-limb hollow pier with wall thickness of $1.0 \mathrm{~m}$ (SLHP with W1.0). The cross sections of different pier types are shown in Fig. 9. The loads imposed were the same as those described in Section VI.A.

The resulting nonlinear and linear stability safety factors are shown in Table VI.

Table VI shows where all four pier types decrease in stability under geometrically nonlinear effects. The double-limb piers decline in stability to nearly the same degree; the two types of single-limb piers decrease to greater extent overall. This is because at the largest cantilever stage, buckling occurs along the bridge while there is less displacement at the pier top along the bridge comprised of double-limb piers than single-limb piers. The inclusion of geometrically nonlinear effects also resulted in a greater decrease in stability in single-limb piers under large deformation theory.

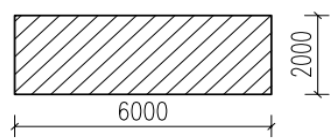

(a) One limb of DLP

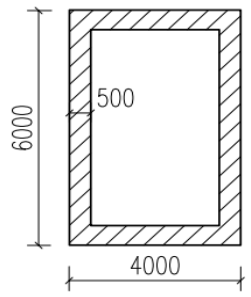

(b) SLHP with W0.5

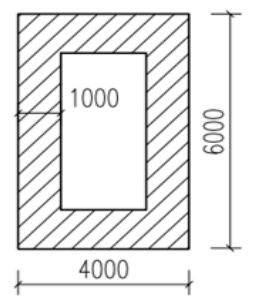

(c) SLHP with 1.0
Fig. 9. Cross sections of four pier types (unit: $\mathrm{mm}$ ).
TABLE VI: LINEAR AND NONLINEAR STABILITY SAFETY FACTORS OF DIFFERENT PIER TYPES

\begin{tabular}{llll}
\hline \hline Pier type & $\begin{array}{l}\text { Linear } \\
\text { stability } \kappa\end{array}$ & $\begin{array}{l}\text { Nonlinear } \\
\text { stability } \kappa_{\mathrm{n}}\end{array}$ & $\begin{array}{l}\left(\kappa-\kappa_{\mathrm{b}}\right) / \kappa \\
(\%)\end{array}$ \\
\hline DLP with CB & 25.78 & 21.04 & 18.4 \\
DLP without CB & 10.81 & 8.05 & 18.1 \\
SLHP with W0.5 & 21.93 & 17.17 & 21.7 \\
SLHP with W1.0 & 22.92 & 18.20 & 20.6 \\
\hline \hline
\end{tabular}

\section{CONCLUSIONS}

In this study, we investigated the stability of curved CRFB models at the largest cantilever stage under geometrical nonlinearity. The GNS of curved CRFBs were studied in an ideal state, with initial material imperfection, in an initial tilt sate, in an initial bend state, and with four different pier types, respectively. Our conclusions can be summarized as follows.

(1) The stability safety factors of the curved CRFB decrease when nonlinearity is considered even in an ideal state.

(2) The stability safety factors decrease to greater extent when initial material imperfections appear in the middle and lower part of the pier compared to upper parts of the pier. A slight difference at the cross section of double-limb piers further degrades the stability.

(3) When there is an initial tilt in the pier, there is little change in linear stability and slight decline in nonlinear stability. In the initial bend state, the linear stability declines slightly and nonlinear stability declines significantly. In practice, priority should be given to controlling for initial bend.

(4) The GNS values of four pier types were compared at the largest cantilever stage to find that those of double-limb piers behave very similarly, while those of single-limb piers are affected to greater extent and differ slightly under varying conditions.

\section{ACKNOWLEDGMENT}

This work was supported by the National Natural Science Foundation of China (U1304515). The authors would also like to thank the anonymous reviewers for their valuable comments and suggestions.

\section{REFERENCES}

[1] Z. Y. Wang, Y. Zhao, and X. Xu, "Three dimension stability of bridge with high piers," Journal of Chang'an University (Natural Science Edition), vol. 23, no. 4, pp. 38-40, 2003

[2] J. L. Wang and S. H. He, "Nonlinear stability and model test of reinforced concrete for high piers," Journal of Chang'an University (Natural Science Edition), vol. 25, no. 4, pp. 31-34, 2005.

[3] S. A. Mirza and A. L. Edward, "Comparative study of strength-computation methods for rectangular reinforced concrete columns," Structural Journal, ACI, vol. 99, no. 4, pp. 399-410, 2002.

[4] J. L. Wang and S. H. He, "Nonlinear stability with high of long-span curve rigid bridge piers in whole process," Journal of Chang'an University (Natural Science Edition), vol. 28, no. 3, pp. 48-52, 2008.

[5] Z. Fang, F. Wang, and C. L. Cao, "Nonlinear stability analysis of long-span continuous rigid bridge with double thin-wall high piers at its cantilever state," Engineering Mechanics, vol. 26, no. 7, pp. 155-162, 2009.

[6] W. L. Bai, Y. Zhang, X. F. Shi, and X. Ruan, "Influence parameters of stability of continuous rigid frame bridge with long span and high piers in mountainous area," Journal of Chongqing Jiaotong University (Natural Science), vol. 32, no. Sup.1, pp. 839-8430+851, 2013. 
[7] J. Song, M. Zhang, and Y. B. Li, "Stability analysis on high piers with consideration of initial imperfection and multiple loads," $J$. of Chongqing Jiaotong University (Natural Science), vol. 21, no. 2, pp. 199-202+330, 2012

[8] J. L. Wang and S. H. He, "Nonlinear stability analysis of long-span curve bridge with high piers during cantilever construction," Journal of Traffic and Transportation Engineering, vol. 6, no. 2, pp. 30-34, 2006.

[9] J. L. Wang and S. H. He, "Central angle influence of long-span curve bridge on its inner forces, displacements and stability," Journal of Traffic and Transportation Engineering, vol. 7, no. 3, pp. 86-90, 2007.

[10] A. Sevket, "Numerical modelling of continuous concrete box girder bridges considering construction stages," Applied Mathematical Modelling, vol. 35, no. 8, pp. 3809-3820, 2011

[11] N. Mohammad, C. Tanusree, and M. Vasant, "Nonlinear buckling analysis of slender piles with geometric imperfections," Journal of Geotechnical and Geoenvironmental Engineering, ASCE, vol. 141, no, 1, pp. 06014014:1-8, 2015.

[12] Q. Zhao, B. Yu, E. G. Burdette, and J. S. Hastings, "Monitoring steel girder stability for safer bridge erection," Journal of Performance of Constructed Facilities, ASCE, vol. 23, no. 6, pp. 391-398, 2009.

[13] X. H. Feng, Z. Q. Zhu, and X. Q. He, "Geometrical nonlinear analysis for multi-parameters of four tower cable-stayed bridge based on the bar element model," in Proc. International Conference on Structure. Mechanical and Materials Engineering, pp. 137-141, 2015.

[14] Q. Z. Luo and Y. J. Chen, "Geometric nonlinear analysis of curved box continuous girders considering shear lag effect," Advanced Materials Research, vol. 243-249, pp. 1811-1816, 2011.

[15] Z. S. Harper, S. T. Edwards, G. R. Consolazio, and K. R. Gurley, "Drag coefficients for construction-stage stability analysis of bridge girders under wind loading," Journal of Bridge Engineering, ASCE, vol. 22, no. 1 , pp. 1-14, 2017.

[16] JTGT D60-01-2015, Wind-resistant Design Specification for Highway Bridges, China Communications Press, China: Beijing, 2015.

[17] F. Tang and J. D. Li, "Stability of long-span continuous rigid-frame bridge with high piers in mountain areas in different construction stage and relevant parameter influence analysis," Journal of Railway Science and Engineering, vol. 13, no. 3, pp. 506-511, 2016.

[18] X. F. Sun, X. S. Fang and L. T. Guan, Mechanics of Materials, High Education Press, Beijing, China, 2008.
[19] JTG D60-2015, General Specifications for Design of Highway Bridges and Culverts, China Communications Press, Beijing, China, 2015.

[20] F. Wang, S. P. Tian and Y. Zhuo, "Analysis of stability of long-span continuous rigid frame bridge with high pier," J. of Railway Eng. Society, vol. 10, 2012, pp. 57-62.

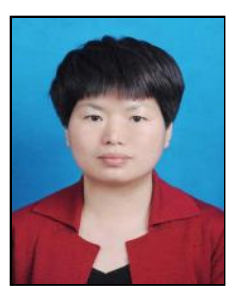

Guohua Song received the B.S. degree in civil engineering from Zhengzhou University of Technology (new name now: Zhengzhou University) in 1996, the M.S. degree in structure engineering from Hefei University of Technology in 1999, and the Ph.D. degree in structure engineering from Beijing University of Technology in 2006. From 1999 she serves the School of Civil Engineering, Zhengzhou University as a teacher, now she is an associate professor. In 2017 she worked in the University of Nottingham, UK, as an academic visitor for one year. Her research area includes mechanical behaviors of curved bridges and prefabricated buildings.

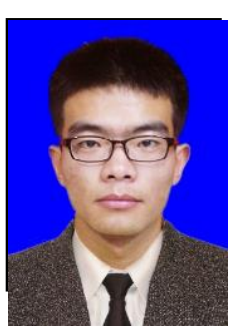

Minghui $\mathbf{L i}$ received the B.S. degree in civil engineering from Henan University of Technology in 2014, the M.S. degree in architectural and civil engineering from Zhengzhou University in 2017. From 2017 he serves the China Construction First Building (Group) Corporation Limited as an assistant engineer, and works on layout design.

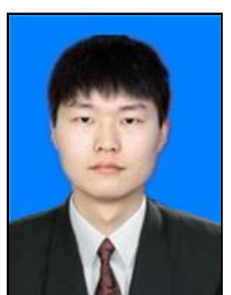

Delu Che received the B.S. degree in civil engineering from Northeast Electric Power University in 2014, and the M.S. degree in structure engineering from Zhengzhou University in 2017. From 2017 he serves Henan Provincial Communications Planning and Design Institute Corporation Limited as an assistant engineer, and works on bridge testing. 